\title{
DARKROOM OUTFLOW TEST IN UNILATERAL CLOSED-ANGLE GLAUCOMA*
}

\author{
BY \\ WALLACE S. FOULDS \\ Addenbrooke's Hospital, Cambridge $\dagger$
}

MACKENZIE (1854) noted that where glaucoma had affected one eye it usually extended also to the other. In closed-angle glaucoma, a disease largely determined by anatomical factors, the similarity of fellow eyes in any one patient is likely to result in the bilateral, rather than unilateral incidence of the disease, and in fact there is a strong body of opinion in favour of a prophylactic peripheral iridectomy in the second eye of a patient who has suffered a unilateral acute attack of glaucoma (Scheie, 1949; Chandler, 1952; Barkan, 1954; Winter, 1955; Sugar, 1957).

Bain (1957) investigated the fate of the second eye in 200 cases of acute unilateral closed-angle glaucoma and found that more than half of these eyes developed clinical evidence of glaucoma over the course of 4 to 5 years. Sixty of these second eyes were submitted to the darkroom test and a positive rise in ocular tension was obtained in ten. Bain suggested that a more efficient provocative test would have disclosed evidence of the disease in a greater number of these eyes.

As the darkroom outflow test (Foulds, 1956) has been found to be more sensitive than the standard darkroom test, it was used to investigate the second eye of 79 cases of apparently unilateral closed-angle glaucoma, and the results are presented below.

Of the 79 patients investigated, each had either had an acute attack of glaucoma in one eye or else one eye had been seen in a sub-acute attack with a closed angle and raised ocular tension. Seventeen of these cases had symptoms (haloes) suggestive of glaucoma in the second eye, while the remaining 62 were symptom-free. All were submitted to a darkroom test of one hour's duration, the ocular tension and facility of aqueous outflow being determined before and after the period in the dark. A rise of more than $8 \mathrm{~mm}$. $\mathrm{Hg}$ was regarded as a positive result with the test, as was a fall of more than 30 per cent. in outflow level.

In the 79 eyes tested, a positive rise in ocular tension occurred in $22(27.8$ per cent.), whereas a marked decrease in the facility of outflow was found in 45 (57 per cent.), a difference which is significant $\left(\chi^{2}=12.07 ; n=1\right.$; $P=<0.001)$.

* Received for publication January 14, 1959.

+ Incorporating work carried out at the Glaucoma Clinic of the Institute of Ophthalmology. Director of Research: Sir Stewart Duke-Elder. 
The results of the test were analysed to determine the significance of the presence or absence of symptoms. Consideration was given first to the change in ocular tension. Of the seventeen eyes with symptoms suggestive of glaucoma, eight gave a positive rise in tension with the test $(47 \cdot 1$ per cent.), compared with fourteen positive results in the remaining 62 eyes which were symptom-free $(27 \cdot 5$ per cent.).

As was expected, a significantly greater number of those eyes with symptoms of the disease showed a positive rise in ocular tension with the test $\left(\chi^{2}=7 \cdot 34 ; n=1 ; P=<0.001\right)$, but it is to be noted that, even so, the test was negative in more than half the cases which could be diagnosed clinically as having closed-angle glaucoma.

When the change in the facility of outflow with the test was considered, it was found that in fourteen of the seventeen eyes (82.4 per cent.) with symptoms, the test was followed by a decrease in the facility of outflow of more than thirty per cent. of the initial level, while in one other case the level of outflow was already abnormally low at the start of the test $(c=0.05)$. Of the 62 eyes which were symptom-free, thirty ( $48 \cdot 4$ per cent.) showed a positive result with the darkroom outflow test. Although the darkroom outflow test was positive in nearly all eyes exhibiting symptoms of the disease, it was also positive in a large number of those which were symptom-free, and in fact the incidence of positive results with this test was not significantly different in the two categories $\left(\chi^{2}=1 \cdot 40 ; n=1 ; P=>0 \cdot 10\right)$.

\section{Discussion}

As would be expected from anatomical considerations, definite evidence of closed-angle glaucoma can be demonstrated in the second eye of the majority of cases wherein the disease appears to be unilateral. The fact that the darkroom test frequently fails to provoke a rise in ocular tension, even where there are symptoms of glaucoma, underlines the fact that, although a positive result is of great significance, no reliance should be placed on a negative darkroom test in the diagnosis of closed-angle glaucoma. While it is true that the darkroom outflow test was positive in the majority of the eyes investigated, it is likely that it too failed to disclose evidence of the disease in some of the eyes which were affected. Even so, the high proportion of positive results with this test in the present series lends support to the view that a prophylactic peripheral iridectomy should be performed on the second eye in cases of apparently unilateral closed-angle glaucoma, provided that this eye is anatomically similar to the affected one.

\section{Summary}

A group of 79 cases of unilateral closed-angle glaucoma was investigated by means of the darkroom and darkroom outflow tests, to see whether there was evidence of the disease in the apparently unaffected eye. The darkroom 
test was positive in 27.8 per cent. of the eyes tested, and the darkroom outflow test was positive in 57 per cent. The results of the two tests were correlated with the presence or absence of symptoms. The significance of the findings in relation to the treatment of closed-angle glaucoma is discussed.

I acknowledge with thanks the helpful criticism given me by Sir Stewart Duke-Elder in the preparation of this paper.

\section{REFERENCES}

BAIN, W. E. S. (1957). Brit. J. Ophthal., 41, 193.

BARKAN, O. (1954). Amer. J. Ophthal., 37, 504.

CHANDLER, P. (1952). A.M.A. Arch. Ophthal., 47, 695.

FouLDs, W. S. (1956). Trans. ophthal. Soc. U.K.., 76, 83.

MACKENZIE, W. (1854). "A Practical Treatise on the Diseases of the Eye", 4th ed., p. 895. Longman, Brown, Green, and Longman, London.

ScheIE, H. G. (1949). Trans. Amer. Acad. Ophthal. Otolaryng., 53, 207.

SUGAR, H. S. (1957). " "The Glaucomas", 2nd ed., p. 272. Hoeber, New York.

WINTER, F. C. (1955). Amer. J. Ophthal., 40, 557. 